\title{
A contribuição das competências infocomunicacionais na atuação do arquivista enquanto mediador
}

\author{
Gleise da Silva Brandão \\ Mestra; Universidade Federal da Bahia, Salvador, BA, Brasil; \\ gleise.br@gmail.com \\ Jussara Borges de Lima \\ Doutora; Universidade Federal da Bahia, Salvador, BA, Brasil; \\ jussarab@ufba.br
}

\begin{abstract}
Resumo: O objetivo do artigo é analisar as competências infocomunicacionais desenvolvidas pelos arquivistas e a sua contribuição no processo de mediação e formação de usuários de informação. A pesquisa tem abordagem qualiquantitativa. Em relação aos procedimentos metodológicos, adotou-se pesquisa bibliográfica e de campo, tendo o questionário online como técnica de coleta de dados; a amostra é composta por 53 arquivistas que atuam nos arquivos brasileiros (públicos e privados). A análise dos dados baseia-se, prioritariamente, nas categorias de análise e nos indicadores desenvolvidos para aferir as competências infocomunicacionais dos arquivistas. Os resultados mostraram que, de forma geral, as competências infocomunicacionais estão mais desenvolvidas no que diz respeito a identificar a necessidade de informação, buscar e avaliar a informação, estabelecer e avaliar a comunicação. Contudo, identificou-se que os arquivistas apresentam dificuldades tanto para se apropriar das informações que têm acesso, quanto para atuar participativa e colaborativamente. Dessa forma, conclui-se que o desenvolvimento dessas competências influencia diretamente na percepção de seu papel enquanto mediador da informação e, também, na sua atuação.
\end{abstract}

Palavras-chave: Competências infocomunicacionais. Arquivista. Mediação da informação.

\section{Introdução}

Os estudos e as práticas envolvendo a mediação da informação e a formação de usuários têm sido bastante recorrentes em áreas como a Biblioteconomia e a Ciência da Informação, porém ainda são pouco abordados no contexto arquivístico brasileiro. Considerando uma sociedade contemporânea cada vez 
mais alicerçada pelo uso da informação, parece imprescindível que o arquivista venha a atuar, também, na formação de usuários de informação.

Nessa perspectiva, considera-se importante que o arquivista estabeleçase como agente mediador da informação - responsável pela intermediação entre a informação, os serviços de informação e o usuário - haja vista que a sua prática profissional inclui orientar e instruir seus usuários no processo de busca e uso das informações. Partindo do pressuposto de que todo o fazer arquivístico envolve, notoriamente, tornar acessíveis as informações ao usuário e que, ao desenvolver atividades como identificar, analisar, avaliar e disseminar a informação, o arquivista está, mesmo que implicitamente, estabelecendo uma relação com os usuários, por meio dos serviços de informação, acredita-se, então, que o arquivista tem potencial para atuar na mediação da informação.

Cabe ressaltar que autores e estudiosos da literatura da área distinguem diversos tipos de mediação da informação como, por exemplo, mediação custodial (profissional como custodiador da informação), mediação passiva (usuário apenas como consumidor) e mediação pós-custodial (usuário participante e ativo na construção de sentido) (SILVA, 2010). Este trabalho tem como foco a mediação pós-custodial que considera o usuário como sujeito ativo diante de suas necessidades informacionais. Procura-se, portanto, compreender seu comportamento perante a informação e a comunicação.

A mediação da informação promovida pelo arquivista é um processo que envolve a competência em informação - conjunto de conhecimentos, habilidades e atitudes para saber buscar e usar as informações - que visa à apropriação da informação. No entanto, também são necessárias competências para se comunicar e se relacionar com o usuário - aqui chamadas de competências em comunicação. A confluência entre essas competências pode ser entendida por competências infocomunicacionais.

Assim, as competências infocomunicacionais podem ser aliadas no processo de mediação da informação e trazer contribuições para a formação de usuários. Essa proposição coaduna-se à ideia defendida por Almeida Junior (2009) de que a mediação da informação é um processo que vai desde o 
tratamento da informação até o atendimento ao usuário. Portanto, o mediador necessita desenvolver competências para saber lidar com a informação e se comunicar com o usuário nessa ação de negociação e para entendê-lo e ajudá-lo a satisfazer sua necessidade. Nesse sentido, objetiva-se analisar as competências infocomunicacionais desenvolvidas pelos arquivistas e sua contribuição no processo de mediação e formação de usuários de informação.

Os resultados apontam que os arquivistas empregam competências infocomunicacionais como identificar a necessidade de informação, buscar e avaliar a informação, estabelecer e avaliar a comunicação. No entanto, apresentam dificuldades para se apropriar das informações que têm acesso e para manter uma postura mais participativa e colaborativa. Tal situação acaba por interferir na percepção do seu papel enquanto mediador e, consequentemente, no seu fazer profissional.

\section{As competências infocomunicacionais}

A forma como se tem acesso à informação e como ela é consumida pelos cidadãos no século XXI, bem como a maneira de conectar-se, interagir e trabalhar com outros reforça a importância de avançar nos estudos sobre o desenvolvimento de competências que possibilitem aos indivíduos saber buscar e usar informações, a fim de torná-los independentes no processo de apropriação informacional e satisfazer suas próprias necessidades. Além disso, um ambiente interativo e dinâmico, como o ciberespaço, que possibilita a esses indivíduos argumentar e defender opiniões, conectar-se e criar laços sociais, participar ativamente não só como espectadores, mas também como produtores torna evidente a demanda por outras competências que estão ligadas ao saber interagir e relacionar-se com o outro: competências em comunicação.

Nessa perspectiva, defende-se o conceito de competências infocomunicacionais que podem ser entendidas como um processo interacional que envolve a capacidade de operar aparatos tecnológicos, tanto para lidar com a informação (localização, avaliação e aplicação), quanto para propiciar o estabelecimento e a manutenção da comunicação e o desenvolvimento de laços 
sociais de interação e colaboração, especialmente no ciberespaço. $\mathrm{O}$ foco nesse ambiente deve-se à constatação de que este é o espaço no qual se tem acesso às principais fontes de informação na atualidade, e para onde vem migrando boa parte das relações interpessoais via uma infinidade de aplicativos e redes de sociabilidade. Assim, Borges (2011) desenvolveu um modelo que procura sistematizar as competências operacionais (que não serão tratadas neste trabalho), competências em informação e em comunicação, unificadas no conceito de competências infocomunicacionais.

A competência em informação está relacionada ao conjunto de conhecimentos, habilidades e atitudes que são exigidos no trato com a informação, no que diz respeito à sua busca, interpretação e uso. Dudziak (2010, p. 11) corrobora ao afirmar que a competência em informação inclui "a capacidade de leitura e escrita, busca e uso da informação, organização e manipulação de dados visando à produção de novas informações e conhecimentos, sua disseminação e preservação visando reuso futuro.”.

De acordo com Jacobson e Mackey (2013), precursores do conceito de metaliteracy, o ambiente de informação sofreu alterações na última década e, com isso, o que se entendia por ser competente em informação não é mais suficiente. Isto levou a um recente aumento da atividade no campo da informação acerca de modelos relacionados à alfabetização, padrões e objetivos de aprendizagem.

Diante disso, Jacobson e Mackey (2013, p. 84, tradução nossa) defendem o conceito metaliteracy que pode ser visto como "[...] um modelo abrangente em relação à competência em informação para promover o pensamento crítico e a reflexão em mídia social, contextos de aprendizagem abertos e comunidades online" ${ }^{\text {. }}$ Observa-se que esse conceito não desconsidera os pilares da competência em informação. Pelo contrário, apoia-se nisso para expandir o conceito para uma dimensão mais crítica e metacognitiva. Nesse sentido, Jacobson e Mackey (2013, p. 84, tradução nossa) defendem que: 
O componente metacognitivo é central no modelo da metaliteracy, este incentiva alunos a refletir continuamente sobre o seu próprio pensamento e desenvolvimento da alfabetização nesses espaços em rede fluidos. Esta abordagem expande as competências para se adaptarem às mudanças em curso nas tecnologias emergentes e para o avanço do pensamento crítico e capacitação para a produção, conexão e distribuição de informação como aprendizes independentes e colaborativos. ${ }^{2}$

Essa nova perspectiva chama a atenção para a necessidade de repensar o comportamento informacional, no sentido de que, para além de saber lidar com a informação e os espaços informacionais, é preciso, também, saber lidar com as próprias destrezas, deficiências e/ou dificuldades de aprendizado. Isto demanda novas competências a serem desenvolvidas pelo indivíduo que precisará conhecer a si mesmo, avaliar seus próprios conhecimentos, habilidades e atitudes ante a assimilação e a apropriação da informação e ser o protagonista no processo de aprendizado.

Observa-se que o conceito de competência em informação agregado à metaliteracy nos permite estreitar as relações das competências informacionais e comunicacionais. Uma evidência está na criação e no compartilhamento de conteúdo, porque se demanda tanto competências para lidar com a informação (competências em informação) quanto aquelas que são concretizadas a partir da relação com o outro (competência em comunicação). Ao produzir um vídeo, por exemplo, o indivíduo certamente terá que apoiar-se em informações já existentes, sintetizá-las, conectá-las e, ainda, avançar com sua própria perspectiva. Contudo, raramente se produz algo se não for para compartilhar, disseminar e, assim, entram em cena as competências em comunicação: para quem disseminar, em que canal e com qual linguagem.

Vê-se, portanto, que o compartilhamento de informações demanda socialização e conexão entre as pessoas e que essa conexão estimula a criação de novos conteúdos. Isso significa dizer que, para além de lidar com a informação que está registrada nos espaços informacionais, o indivíduo precisa, também, lidar com a informação que não está registrada, as informações que cada um carrega ou explicita a partir dos seus próprios conhecimentos, o que envolve a relação com o outro. González Fernández-Villavicencio (2012) corrobora ao 
entender essa necessidade por novas competências como o reflexo do impacto das tecnologias na vida de todos, que resultam em mudanças na forma como nos comunicamos, acessamos a informação, nos conectamos com colegas, amigos, aprendemos e, até mesmo, como nos socializamos.

Essas novas competências são entendidas aqui como competências em comunicação, que se referem "[...] à capacidade de estabelecer interação com outras pessoas ou grupos, trocar, criticar e apresentar as informações e ideias de forma a atingir uma audiência e com ela manter uma relação bilateral." (BORGES; BRANDÃO, 2014, p. 133). Siemens (2010) relaciona o desenvolvimento do conhecimento com a capacidade de comunicação:

Em vez de ver o conhecimento de uma perspectiva única (o filtro) nós, como indivíduos podemos contribuir com as nossas opiniões e pontos de vista para estender a profundidade (diversidade) da nossa compreensão. $\mathrm{O}$ conhecimento agora pode ser expresso através do conjunto de indivíduos, um crescendo ensurdecedor de opiniões e pontos de vista opostos e complementares. ${ }^{3}$ (SIEMENS, 2010, p. 72, tradução nossa).

Diante disso, a competência em comunicação envolve também a capacidade de argumentar, de ser articulado e crítico, e de apresentar as informações e ideias de forma a atingir uma audiência. Wolton (2006, p. 175) também contribui ao salientar que a comunicação não é um processo unilateral e, portanto, para que seja efetiva há de se considerar o outro:

Comunicar não é apenas produzir e distribuir informação, é também ser sensível às condições nas quais o receptor a recebe, aceita, recusa, remodela em função das suas escolhas filosóficas, políticas, culturais.

As competências infocomunicacionais podem ser vistas sob a perspectiva da mediação desenvolvida pelo arquivista, isso porque a mediação é compreendida como um processo colaborativo capaz de promover a apropriação da informação e, por conseguinte, um salto qualitativo nos usuários. Defende-se que o desenvolvimento de competências infocomunicacionais associado à mediação da informação pode propiciar esse salto qualitativo tanto no usuário, 
ao tornar-se independente na satisfação de suas necessidades informacionais, quanto no profissional que potencializa seu papel de mediador.

A mediação da informação pode ser entendida como um processo relacional que envolve a tríade: profissional da informação, informação e usuário, visando à apropriação da informação a partir de uma necessidade informacional. Isso não significa que tal processo seja estático e linear, pois está sujeito a várias interferências, inclusive do profissional que, ao mediar a informação, interfere no processo consciente ou inconscientemente.

Diante disso, para Almeida Júnior (2009) a mediação da informação tem como ponto fundamental a interferência, em oposição à ideia de neutralidade que torna a mediação estática e unidirecional. Nessa perspectiva, define a mediação da informação como:

[...] toda ação de interferência - realizada pelo profissional da informação -, direta ou indireta; consciente ou inconsciente; singular ou plural; individual ou coletiva; que propicia a apropriação de informação que satisfaça, plena ou parcialmente, uma necessidade informacional. (ALMEIDA JÚNIOR, 2009, p. 92).

A mediação da informação pode estimular e promover um salto qualitativo nos sujeitos, o que é entendido como "a mudança de um estado para outro, distinguindo-se de outras transformações por ser evidente na realidade da matéria." (NEVES, 2011, p. 413). Assim, a relação entre as competências em informação e a mediação já está sedimentada na literatura (MIRANDA, 2006; NEVES, 2011). Por outro lado, se considerarmos que a mediação da informação é um processo de negociação, fica evidente que o mediador precisa empregar competências em comunicação para promover o diálogo, a troca e a interação com o usuário sob a perspectiva da mediação pós-custodial.

Dessa forma, na medida em que as competências em informação ajudam a lidar com a informação e os processos informacionais, as competências em comunicação contribuirão para firmar uma relação bilateral nesse processo de negociação. Diante disso, é preciso compreender como o emprego de competências infocomunicacionais pode contribuir para o processo de mediação, a partir de uma perspectiva colaborativa entre arquivistas e usuários. 


\section{Competências infocomunicacionais empregadas pelos arquivistas}

Nesta seção, serão apresentadas as competências infocomunicacionais empregadas pelos arquivistas brasileiros e sua contribuição para o processo de mediação e formação de usuários. A pesquisa possui abordagem qualiquantitativa. Quanto aos procedimentos metodológicos adotou-se pesquisa bibliográfica e de campo, tendo o questionário online como técnica de coleta de dados. O questionário foi enviado por meio de grupos e comunidades online que reúnem profissionais da área. A amostra é composta por 53 arquivistas que atuam nos arquivos brasileiros (públicos e privados) e trata-se de uma amostragem não probabilística por acessibilidade, na qual não se tem a pretensão de atingir a uma representação estatística de todos os arquivistas brasileiros, mas obter informações daqueles que se dispõem a participar. A análise dos dados estabeleceu-se em três níveis: descrição, comparação e interpretação, de acordo com Guerra (2010, p. 62):

Nesse sentido, a análise de conteúdo tem uma dimensão descritiva que visa dar conta do que nos foi narrado e uma dimensão interpretativa que decorre das interrogações do analista face a um objecto de estudo, com recurso a um sistema de conceito teóricoanalítico cuja articulação permite formular as regras de inferência.

Assim, foram criadas categorias de análise e indicadores a partir da pesquisa bibliográfica (Quadro 1). Os indicadores estão sinalizados em negrito no corpo do texto.

Quadro 1- Indicadores de verificação das competências

\begin{tabular}{|c|c|c|}
\hline & INDICADORES & CRITÉRIOS DE ANÁLISE \\
\hline \multirow{3}{*}{ 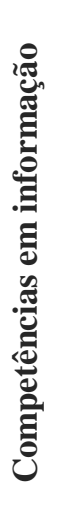 } & $\begin{array}{l}\text { Identificar a necessidade } \\
\text { de informação }\end{array}$ & $\begin{array}{l}\text { Definir a necessidade informacional. Avaliar o próprio } \\
\text { conhecimento. Explorar e buscar informações. } \\
\text { Personalizar as ferramentas de busca. }\end{array}$ \\
\hline & Acessar às informações & $\begin{array}{l}\text { Escolher um sistema de busca. Definir estratégias e } \\
\text { terminologia adequada. Utilizar operadores booleanos, } \\
\text { filtros e ferramentas adequadas. Compreender os formatos } \\
\text { da informação. }\end{array}$ \\
\hline & Avaliar a informação & $\begin{array}{l}\text { Considerar aspectos como pertinência, confiabilidade e } \\
\text { veracidade. Identificar fatos, opiniões e tentativas de } \\
\text { manipulação. Inter-relacionar peças de informação. } \\
\text { Analisar o contexto de produção. Revisar o processo de }\end{array}$ \\
\hline
\end{tabular}




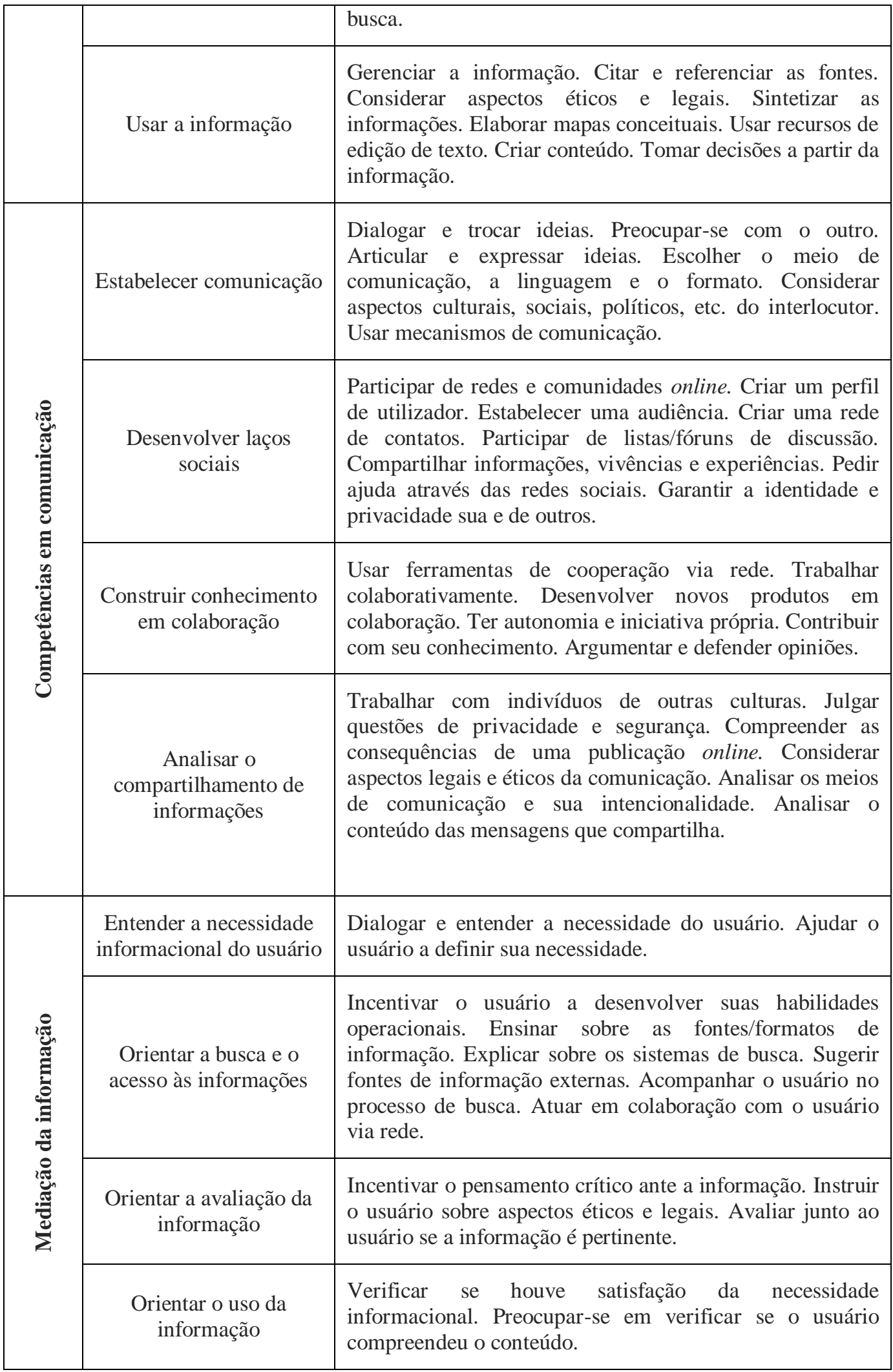

Fonte: Elaborado pelas autoras. 


\subsection{Competências em informação}

Um dos primeiros indicadores das competências em informação a ser analisado é identificar a necessidade de informação. Ao serem questionados sobre o seu comportamento, ao receber uma situação e/ou problema para resolver, 38\% dos arquivistas que participaram da pesquisa responderam que costumam explorar informações online para se familiarizar com o tema quando estão diante de uma necessidade de informação.

Por outro lado, 33\% deles preferem usar o conhecimento prévio para resolver a situação, isso significa que costumam recorrer ao seu próprio conhecimento para atender suas necessidades informacionais. Embora seja importante considerar os conhecimentos prévios no processo de busca, coloca-se uma questão: se não forem identificadas lacunas cognitivas e se não se reconhecer que estas podem ser preenchidas com a busca de informações, então todo o processo de busca e uso das informações pode ser comprometido.

No que diz respeito a acessar as informações, a maioria dos arquivistas $(60,4 \%)$ declara construir estratégias de busca com base na necessidade de informação, porém, observa-se que apenas $24,5 \%$ utilizam operadores booleanos e filtros. O uso de operadores booleanos e filtros são recursos chave para refinar a pesquisa e possibilitar resultados mais próximos ao tema pesquisado. $\mathrm{O}$ fato de a maioria dos arquivistas ignorar ou desconhecer essas técnicas indica que a construção de estratégias de busca adquire um caráter pouco técnico e subjetivo.

Por outro lado, uma parcela significativa $(49,1 \%)$ prefere pesquisar o conteúdo livremente e, a partir dos resultados, ajustar a pesquisa. Isso pode indicar que a busca é realizada sem critérios pré-estabelecidos, podendo assim comprometer a recuperação da informação.

Um aspecto que também interfere na seleção de informações relevantes é o uso de fontes de informação adequadas à necessidade de informação. De acordo com os dados analisados, as três fontes de informação mais utilizadas pelos arquivistas são buscadores ou motores de busca (66\%), artigos publicados em periódicos científicos $(56,6 \%)$ e sites especializados $(52,2 \%)$ como agências, empresas, organismos oficiais, entre outros. Nota-se que o uso de blogs e redes 
sociais ainda é pouco significativo: apenas 13,2\% consideram esses ambientes como uma fonte de informação adequada às suas necessidades informacionais. Independente de qual seja a fonte de informação escolhida, ela precisa ser avaliada. Nesse sentido, os arquivistas apontaram os critérios que costumam aplicar para que se possa garantir que as informações sejam confiáveis e pertinentes.

Os resultados apontam que $71,7 \%$ se preocupam em verificar a autoridade da fonte, 58,5\% confrontam fontes diferentes e 56,6\% comparam com o conhecimento prévio. Significa dizer que, em grande parte, os arquivistas empregam critérios de avaliação da informação. Contudo, ressalta-se que avaliar a informação somente com base na autoridade da fonte não garante que a informação seja pertinente, verídica e confiável, já que muita informação falsa é também disseminada por fontes oficiais. Daí a importância de questionar e analisar, criticamente, todas as fontes de informação e sua intencionalidade, porque as fontes têm forte influência sobre o viés da informação que é fornecida.

Observa-se ainda que $26,4 \%$ dos arquivistas se limitam a utilizar apenas as fontes que já conhecem ou que já utilizaram antes. Dessa forma, parecem deixar de lado a responsabilidade de avaliar as fontes de informação disponíveis na internet. Outro resultado que interessa é que 30,2\% dos arquivistas confiam nas fontes recomendadas por outras pessoas. Acredita-se que este aspecto está muito relacionado às competências em comunicação, visto que a relação entre as pessoas possibilita o desenvolvimento de laços sociais com os quais são criados vínculos de confiança. Assim, coloca-se em questão não só a responsabilidade de quem recebe a informação, mas também de quem a compartilha. As ações desse sujeito perante a informação compartilhada podem ser replicadas por outros que o avaliam como uma fonte confiável.

Os resultados demonstram que os arquivistas também estão preocupados em analisar criticamente o conteúdo das informações que selecionam no processo de busca. Para tanto, costumam aplicar frequentemente critérios pré- 
definidos para avaliar o conteúdo das informações acessadas, conforme aponta o Gráfico 1.

Gráfico 1 - Critérios utilizados para avaliar o conteúdo das informações

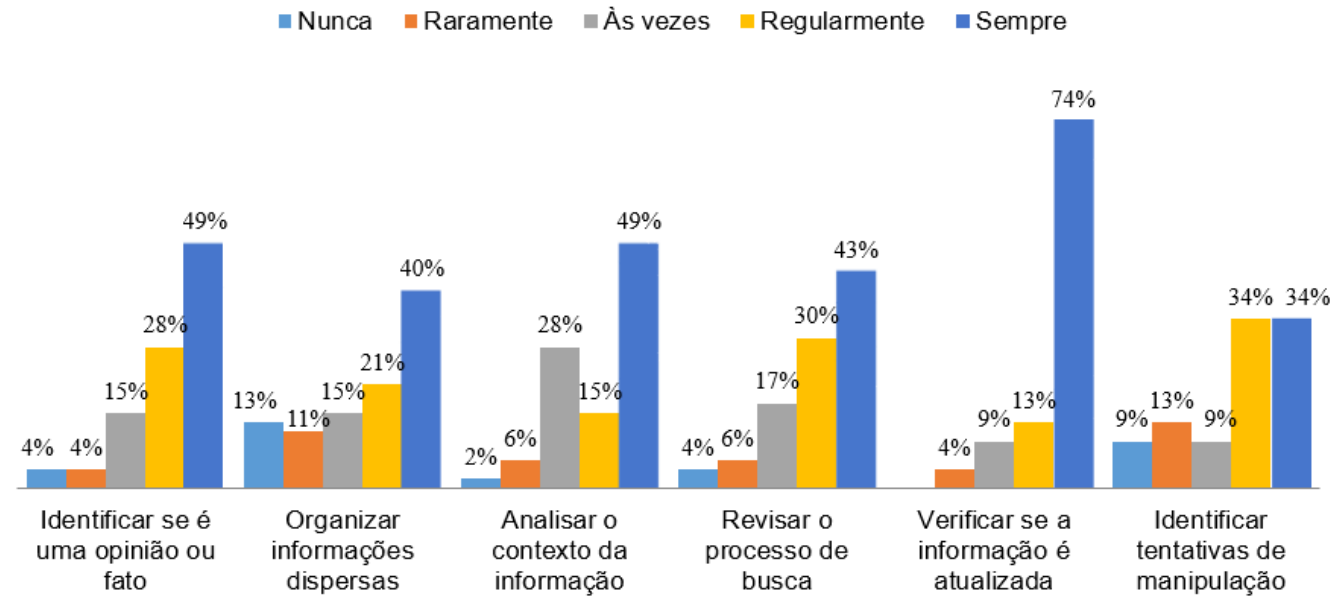

Fonte: Elaborado a partir dos dados da pesquisa.

Os dados evidenciam que um dos critérios utilizados com mais frequência pela maior parte dos arquivistas (74\%) é verificar a atualidade da informação selecionada (Gráfico 1). Por outro lado, os arquivistas mostram-se divididos quanto ao uso de dois critérios: organizar informação dispersas (juntar e inter-relacionar peças de informação dispersas ou desorganizadas) e identificar se há tentativas de manipulação. Percebe-se que esses critérios são os menos indicados, o que mostra que não são considerados como prioridade no que diz respeito à avaliação do conteúdo das informações. Ressalta-se que tais critérios influenciam diretamente na avaliação do teor do conteúdo, assim sua adoção é geralmente aconselhada porque podem ajudar a garantir a credibilidade e confiabilidade da informação.

No que diz respeito ao indicador usar as informações, os resultados da pesquisa mostram que o uso que os arquivistas fazem das informações que foram selecionadas e avaliadas no processo de busca é variado (Gráfico 2). O uso da informação envolve saber como usar as informações acessadas e já 
avaliadas de forma a resolver seu problema, tomar decisões de maneira satisfatória ou transformá-las em conhecimento.

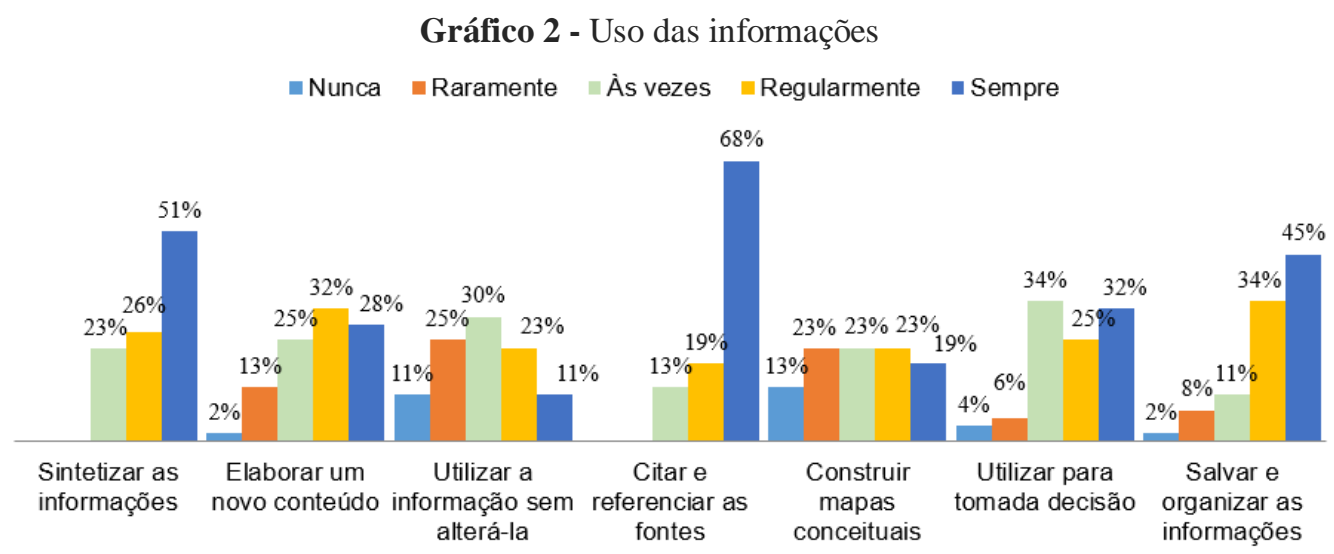

Fonte: Elaborado a partir dos dados da pesquisa.

Ressalta-se como ponto a ser analisado a elaboração de um novo conteúdo a partir das informações selecionadas e analisadas: $28 \%$ dos participantes afirmam produzir novas informações sempre e $32 \%$ o fazem regularmente. Observa-se que boa parte desses profissionais costuma produzir conteúdo a partir das informações a que têm acesso, porém é preciso considerar que $40 \%$ deles não costumam produzir conteúdo com regularidade. Isso representa um resultado significativo no que se refere à assimilação e à apropriação da informação, condição essencial para a produção de conteúdo.

Outros aspectos que estão relacionados à produção de informações são sintetizar as informações (51\%), extraindo delas os pontos principais; e citar/referenciar as fontes utilizadas (68\%), que tiveram grande indicação por parte dos arquivistas. Isso sugere que tais profissionais demonstram preocupação quanto à seleção e reaproveitamento de conteúdo e ainda consideram os aspectos éticos e legais do reuso da informação.

Observa-se que os arquivistas costumam priorizar a organização física das informações, indicada pela opção "salvar e organizar as informações" (45\%) para recuperá-las posteriormente, se comparada à organização conceitual representada pela opção "construir mapas conceituais" (19\%). A hipótese é de 
que a formação acadêmica desses profissionais ligada à gestão documental, na qual classificar e organizar documentos e informações são conhecimentos básicos requeridos, impulsionam uma postura mais favorável à organização das informações.

Diante desses resultados percebe-se que, no que se refere ao emprego de competências em informação, os arquivistas reconhecem a necessidade de buscar informações para preencher lacunas cognitivas ou mesmo para solucionar determinada necessidade de informação, conhecem e utilizam de forma satisfatória as fontes de informação disponíveis e, também, têm a preocupação não só de avaliá-las, bem como analisar as informações advindas dessas fontes para saber se são, de fato, confiáveis e pertinentes à sua necessidade.

No entanto, algumas dificuldades e/ou deficiências que foram identificadas relacionam-se ao uso da informação. Apesar de ter sido observado um comportamento direcionado a um perfil mais prossumidor de informação, alguns obstáculos ainda se verificam neste quesito. De acordo com os dados sobre produção de conteúdo, observa-se que uma parcela significativa dos arquivistas ainda encontram obstáculos para se apropriar das informações. Isso pode levá-los a ter dificuldades para conduzir os usuários a atender a sua necessidade informacional ao mediar a informação, uma vez que só pode-se orientar outros quando as informações foram apreendidas e assimiladas.

\subsection{Competências em comunicação}

O uso das ferramentas de comunicação pelos arquivistas não é uniforme. Determinadas ferramentas como, por exemplo, o e-mail e as redes sociais apresentam uso intenso em detrimento de outras que têm baixa frequência de uso como é o caso dos wikis, blogs e fóruns. Observa-se que $75 \%$ dos arquivistas utilizam o e-mail várias vezes ao dia, e 64\% usam as redes sociais online. O Gráfico 3 indica a frequência do uso de ferramentas de comunicação apontada pelos participantes da pesquisa. 


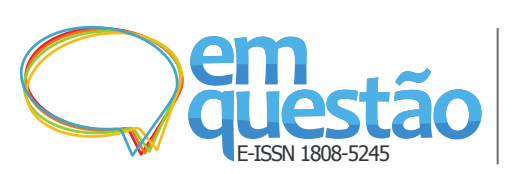

A contribuição das competências infocomunicacionais na atuação do arquivista enquanto mediador

Gleise da Silva Brandão e Jussara Borges de Lima

Gráfico 3 - Frequência do uso de ferramentas de comunicação

$\begin{array}{ll}\text { Várias vezes ao dia } & \square 1 \text { a } 3 \text { vezes ao dia } \quad \text { - } 1 \text { a } 3 \text { vezes por semana } \\ \square 1 \text { a } 3 \text { vezes no mês } & \text { utilizo poucas vezes no ano } \quad \text { Não utilizo }\end{array}$

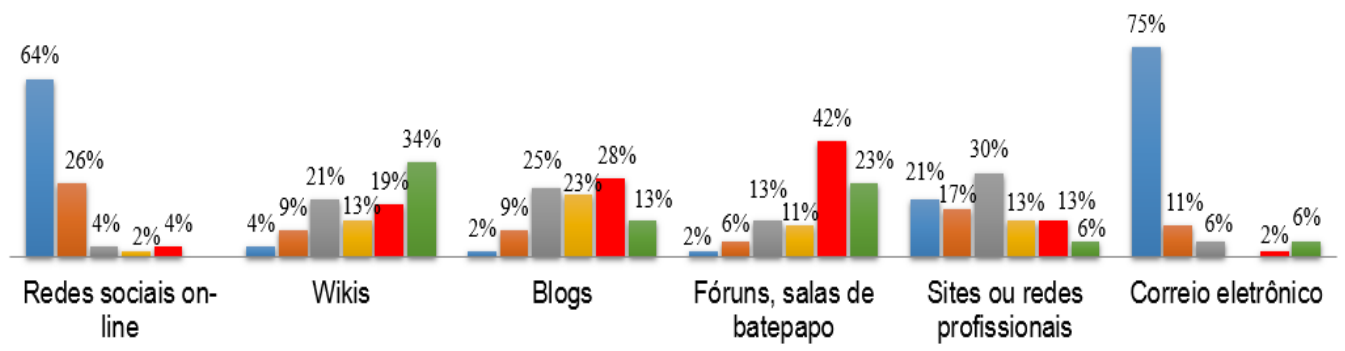

Fonte: Elaborado a partir dos dados da pesquisa.

O uso frequente do correio eletrônico pode ser justificado por esta ser uma ferramenta muito utilizada para fins profissionais. Segundo o Comitê Gestor da Internet no Brasil - CGI.br (2014, p. 157), o envio e o recebimento de e-mails representa $64 \%$ das atividades realizadas pelos usuários de Internet, e é bastante usado entre as faixas etárias de 25 a 44 anos que também representa o grupo mais ativo economicamente. Para o Comitê Gestor da Internet no Brasil, “[...] a hipótese é que, nessa faixa etária, o e-mail seja mais utilizado para fins profissionais, uma vez que é significativa a diferença no uso desse meio de comunicação de acordo com a condição de atividade." (COMITÊ GESTOR..., 2014, p. 157).

Considerando que o uso das redes sociais mostra-se intenso, coloca-se em questão se os arquivistas estão utilizando as redes sociais para fins profissionais ou apenas para entretenimento e assuntos de cunho pessoal. Esse ponto será mais bem explorado a seguir, quando são analisadas as razões que impulsionam os arquivistas a participarem tão ativamente das redes e comunidades online. Dentre as motivações apontadas, o uso para fins profissionais apresenta-se com menor incidência, o que mostra que a participação dos arquivistas nesses ambientes de interatividade ainda é um espaço que pode ser mais explorado.

Os resultados também apontam que wikis e blogs são ferramentas pouco utilizadas pelos arquivistas. Os wikis, bem como os blogs, são ambientes que 
possibilitam a criação de conteúdo em colaboração e seu compartilhamento, já que criam condições favoráveis para a interação e o trabalho colaborativo. Assim, o uso dessas ferramentas não só pode favorecer o aprendizado, bem como o desenvolvimento de competências infocomunicacionais. A criação e compartilhamento de conteúdo em ambientes participativos e colaborativos, como mídias sociais, oferecem o contexto de aprendizagem colaborativa, de acordo Jacobson e Mackey (2013).

Nessa perspectiva, faz-se necessário saber estabelecer a comunicação. Ao serem colocados diante de uma situação que envolveria o uso de uma ferramenta de comunicação - gerir um site ou blog do arquivo com o qual trabalha - os arquivistas demonstraram preocupação em articular e expressar suas ideias de forma clara e objetiva $(58,5 \%)$. Além disso, mostraram estar preocupados em como o usuário recebe e interpreta a sua mensagem ao apontarem como suas prioridades: conhecer o perfil do usuário $(67,9 \%)$, adequar a mensagem e seu formato a depender do que pretende comunicar e ao público $(24,5 \%)$, e interagir com esse usuário $(22,6 \%)$.

Destaca-se aqui que a interação é um ponto chave dentro do conceito de competências em comunicação e pouco explorado pelos arquivistas. O emprego de competências em comunicação está diretamente ligado ao estabelecimento de uma relação bilateral e, por isso, não deve ser considerado como uma mera transmissão de informações (WOLTON, 2006). Para alguns arquivistas, as prioridades seriam a aparência do ambiente (37,7\%), divulgar as funções e atividades realizadas pelo arquivo $(60,4 \%)$ e melhorar e/ou dinamizar o acesso dos usuários à informação (52,8\%). Ainda que sejam ações importantes, elas não envolvem interação e conexão com o usuário, restringindo-se à transmissão de informações, e, portanto, não se alinham à perspectiva da mediação póscustodial que coloca o usuário como partícipe dos processos informacionais.

Nesse sentido, os arquivistas foram questionados sobre seu comportamento quando precisam comunicar-se com outros para atingir determinada necessidade como, por exemplo, ao realizar uma exposição sobre o seu trabalho para colegas de outros departamentos. Nesse sentido, 75,5\% 
procuram ser objetivos, claros e concisos para que sua mensagem seja compreendida pelo outro, porém, apenas 43,3\% dos arquivistas costumam possibilitar a interação com o público, o que indica mais uma vez dificuldades de comunicação. A abertura para o diálogo e a interação são requisitos fundamentais para uma profissão de cunho social, na qual as críticas ou as contribuições advindas dos usuários e colegas são fundamentais para evoluir para uma Arquivologia pós-custodial.

Outras estratégias apontadas foram ser dinâmico e elaborar uma apresentação com variadas ferramentas $(39,6 \%)$ e utilizar recursos audiovisuais como imagens, vídeos, charges, entre outros $(58,5 \%)$, que se contrapõem a apresentar os conteúdos de forma simples, utilizando poucos recursos estratégia utilizada por $35,8 \%$ dos respondentes. Esses dados indicam que os arquivistas, ao se comunicar, preocupam-se, também, em escolher o formato que melhor se adéqua à sua necessidade, e em usar recursos para facilitar a compreensão do público que pretendem atingir.

O conjunto de dados deste indicador revela uma comunicação frágil, uma vez que ela está concentrada na transmissão do conteúdo, em detrimento de uma comunicação forte centrada na interação, na conectividade e na negociação de sentidos. Por isso, para o ato de comunicar, considera-se relevante desenvolver laços sociais que se referem ao estabelecimento de vínculos com outros. De acordo com Siemens (2010), a criação de redes de aprendizagem individuais são condições basilares para o aprendizado colaborativo. Ressalta-se que todos os arquivistas que participaram da pesquisa fazem parte de redes e comunidades online.

Entre as principais motivações dos arquivistas para participar de redes e comunidades online estão: interagir com amigos e/ou conhecer pessoas e buscar informações sobre interesses pessoais, ambos indicados por, aproximadamente, 64\% dos participantes; seguidos por manter-se atualizado sobre notícias em geral $(56,6 \%)$. A partir desses dados, percebe-se que as redes sociais e comunidades online têm sido consideradas também como uma fonte de informação relevante, isso quer dizer que a interação e a conectividade 
permitem aos arquivistas manterem-se atualizados. Essa conectividade tem beneficiado tanto as relações pessoais, como o compartilhamento de informações, vivências e experiências $(47,2 \%)$.

Observa-se que tratar de assuntos profissionais (45,3\%) é uma das motivações menos apontadas pelos arquivistas para sua participação em redes e comunidades online. Como foi visto, ao analisar a frequência (Gráfico 3), o uso de redes sociais pelos arquivistas é bastante intenso. Acredita-se que os arquivistas podem aproveitar sua participação nesses ambientes interativos para potencializar sua função de mediação; não apenas se fazer presente, mas também se mostrar participativo e considerar as redes sociais como um canal de interação direta com os usuários que estão presentes e atuantes nesses espaços.

Nesse sentido, o Gráfico 4 permite analisar o comportamento dos arquivistas nesses ambientes.

Gráfico 4 - Comportamento em redes e comunidades online

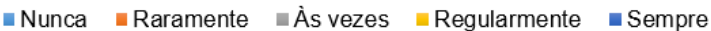

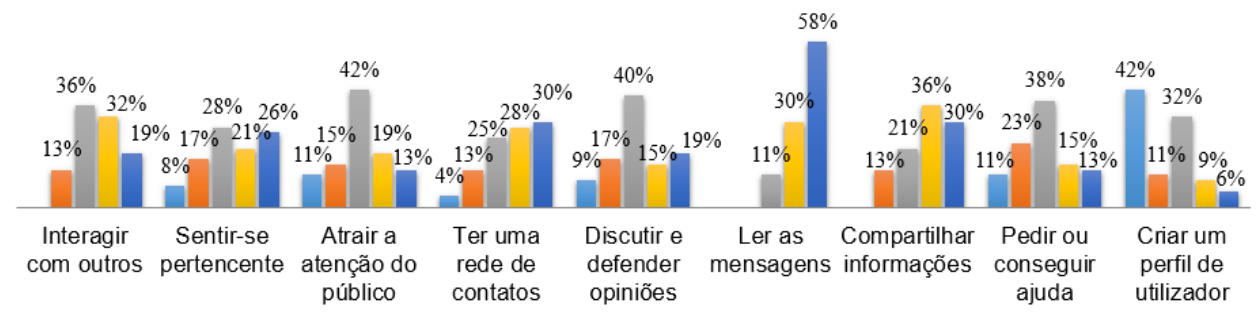

Fonte: Elaborado a partir dos dados da pesquisa.

A interação é um aspecto importante a ser considerado, mas ao que tudo indica os arquivistas estão mais interessados em ler as mensagens recebidas para se manterem informados (58\%) do que interagir com outros (19\%). Outro dado relevante, ainda relacionado a esse aspecto, é que, apesar de afirmarem compartilhar informações com regular frequência (36\%), nem sempre se preocupam em atrair a atenção do público e estabelecer uma audiência a partir 
dos conteúdos que disseminam: apenas 13\% dizem o fazer sempre e 19\%, regularmente.

Outro ponto que precisa ser considerado é o engajamento, ou seja, se estes arquivistas desempenham um papel ativo e participativo dentro dessas redes e comunidades ou apenas fazem parte delas. Observa-se, a partir dos dados apresentados pelo Gráfico 4, que apenas uma pequena parcela dos participantes afirmou participar de discussões e defender opiniões sempre (19\%), ou regularmente (15\%); a maioria deles o fazem às vezes $(40 \%)$. É possível que o fato de esses arquivistas nem sempre se sentirem pertencentes a determinado grupo e/ou comunidade inibe uma participação mais atuante nesses espaços e, consequentemente, a criação de vínculos.

O engajamento ativo, via tecnologias emergentes, é um dos aspectos tratados pela metaliteracy. Para Mackey e Jacobson (2014, p. 13), "as tecnologias emergentes são inerentemente diferentes das impressas e requerem engajamento ativo com vários formatos de informação através de diferentes modalidades de mídia." Acredita-se que o nível de engajamento em ambientes colaborativos favorece a produção criativa e colaborativa, assim, não é a mera presença em redes e comunidades sociais que possibilitará a construção de conhecimento em colaboração.

No entanto, não há um consenso entre os arquivistas em relação a estabelecer e manter uma rede de contatos para ajuda mútua. Esse indicador também influenciará outro: a mobilização das redes sociais para conseguir ajuda quando se precisa. Apenas uma pequena parcela afirma pedir ou conseguir ajuda frequentemente, sendo $15 \%$ regularmente e 13\% sempre. Assim, demonstra-se que a postura dos arquivistas diante do uso das redes e comunidades online ainda é pouco colaborativa e apresenta um caráter mais passivo, no qual se destaca a busca por informações, enquanto a relação e conexão com outros fica em segundo plano.

A participação em redes e comunidades sociais também contribui para construir conhecimento em colaboração. Nesse sentido, cabe também analisar 
se os arquivistas têm dificuldades para trabalhar de forma colaborativa e gerar novos conhecimentos (Gráfico 5).

Gráfico 5 - Grau de dificuldade para trabalhar colaborativamente

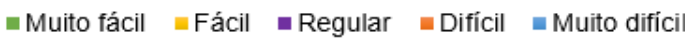

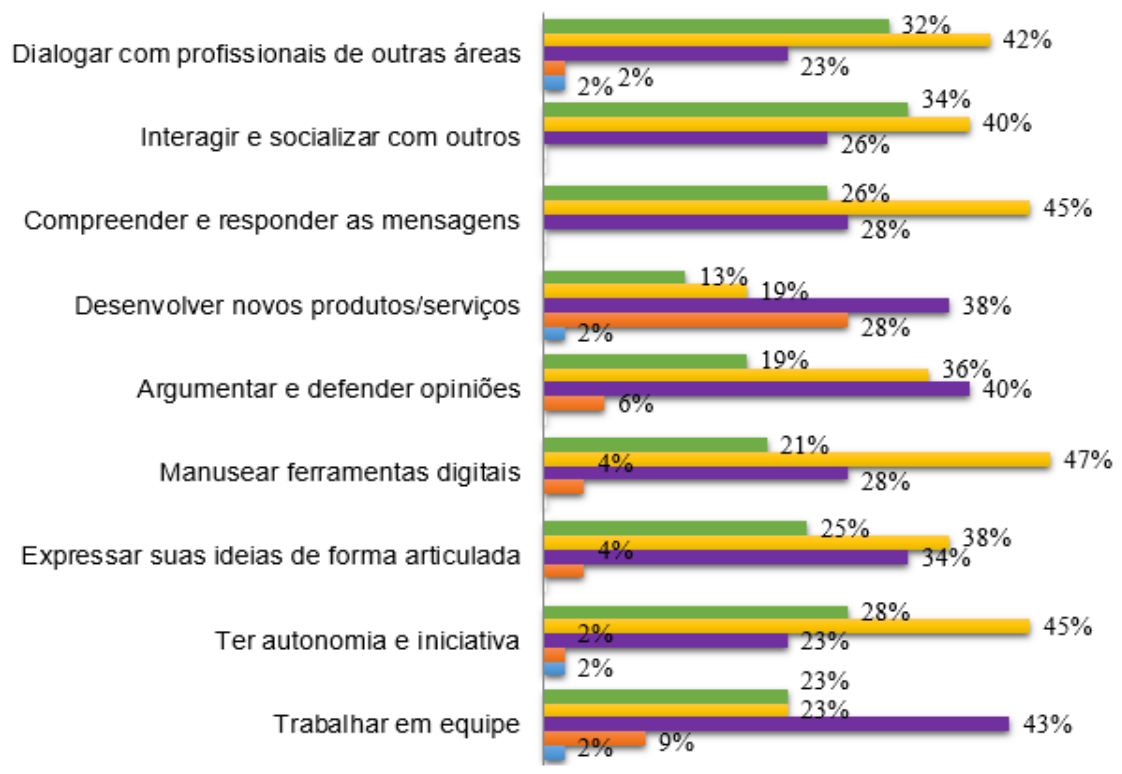

Fonte: Elaborado a partir dos dados da pesquisa.

Vê-se que os arquivistas consideram mais fáceis atividades como manusear as ferramentas de comunicação digitais (47\%), compreender e responder mensagens recebidas $(45 \%)$ e ter autonomia e iniciativa própria (45\%), atividades essas que tem pouco caráter interativo e colaborativo. Portanto, não se trata de exclusão digital, já que não são demonstradas dificuldades para lidar com as ferramentas ou mesmo com a comunicação por via desses meios, visto que o que consideram mais difícil é trabalhar em equipe $(9 \%)$.

A opção “dialogar com profissionais de outras áreas” é considerada fácil para $42 \%$ dos arquivistas e apresenta um caráter interativo que poderia motiválos ao trabalho colaborativo. No entanto, quando parte-se para atividades como trabalhar em equipe e desenvolver novos produtos e serviços colaborativamente percebe-se que o grau de dificuldade aumenta. Assim, acredita-se que esses 
arquivistas podem explorar mais essa facilidade, a fim de dialogar e trocar experiências com outros profissionais para potencializar o trabalho colaborativo. Para Siemens (2010, p. 72), a ascensão do indivíduo potencializa a colaboração: “[...] capacidades de colaboração, socialização e 'fazer as coisas juntos'. Esperamos co-criar e experimentar os modelos de fluxo bidirecional de uso compartilhado do conhecimento e sua difusão." "Contudo, isso implica capacidade para colaborar, participar e construir conhecimento em colaboração.

O grau de dificuldade em atividades como expressar suas ideias de forma articulada, argumentar e defender opiniões que estão mais relacionadas à postura desses arquivistas ante o trabalho colaborativo, ficam entre as categorias "regular" e "fácil", sem significativa diferenciação (a diferença é de apenas $2 \%$ em cada atividade). Isso indica que o maior problema aqui é a relação com o outro.

Além disso, é preciso investigar a postura dos arquivistas quanto a analisar o compartilhamento de informações, que pressupõe apresentar senso crítico diante das mensagens que comunica. Isso significa dizer que, enquanto prossumidor da informação, aquele que compartilha também tem responsabilidades sob o conteúdo da mensagem.

Assim, os arquivistas foram questionados sobre o grau de dificuldade para avaliar determinados aspectos que envolvem o compartilhamento de conteúdos em meio digital. Vê-se que todos os aspectos são considerados pela maioria dos arquivistas como de fácil avaliação. O componente mais fácil para os respondentes é discriminar mensagens indesejáveis (53\%). Aspectos como garantir a segurança e privacidade (45\%) tanto própria quanto alheia e considerar os aspectos legais e éticos (45\%) mostram-se em sintonia em relação às respostas dos arquivistas e, de fato, há uma forte relação entre eles. Os dados podem ser analisados a partir do Gráfico 6.

No entanto, verificar quem é o emissor da mensagem que pretende compartilhar e se esse emissor é confiável parece não ser tão facilmente avaliável quanto os demais aspectos: $43 \%$ dos arquivistas consideraram "fácil" e $36 \%$ indicaram "regular". Diante do exposto, entende-se que o emprego de 
competências em comunicação por parte dos arquivistas contempla, de forma satisfatória, componentes ligados a estabelecer comunicação e a avaliar sua comunicação. No entanto, o desenvolvimento de laços sociais e a construção de conhecimento em colaboração mostram-se menos desenvolvidos devido ao comportamento pouco interativo e colaborativo apresentado pelos arquivistas.

Gráfico 6 - Grau de dificuldade para analisar aspectos do compartilhamento de informações

$$
\text { Muito difícil } \square \text { Difícil } \square \text { Regular } \square \text { Fácil } \square \text { Muito fácil }
$$

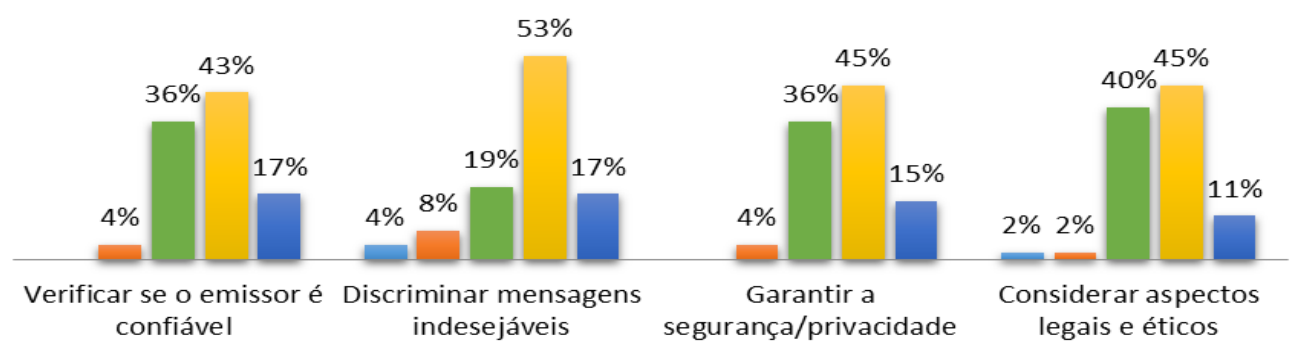

Fonte: Elaborado a partir dos dados da pesquisa.

Conclui-se que os arquivistas precisam desenvolver melhor suas competências, a fim de criar uma postura mais engajada e colaborativa. Jenkins (2009) corrobora ao defender que novas competências são requeridas para atuar em um contexto de cultura participativa como, por exemplo, adequar a produção a determinado público, produzir em cooperação e participar de processos sociais relacionados à sua área de atuação. Assim, o desenvolvimento de competências em comunicação converge com uma postura mais proativa e necessária aos profissionais que fazem a mediação da informação. Quando é demandado aos arquivistas gerenciar ferramentas de comunicação online, por exemplo, o emprego dessas competências fica evidente e, se não houver o trabalho colaborativo e a interação efetiva com o usuário, mesmo o acesso e a apropriação da informação podem ficar comprometidos. 


\subsection{Mediação da informação}

Com base em Ribeiro (2010), a mediação da informação inclui entender o comportamento $\mathrm{e}$ as necessidades informacionais daquele que procura informação e poderá se tornar um utilizador regular. A mediação, nesse sentido, tem o papel de analisar elementos referentes ao acesso e ao uso em relação aos serviços de informação, se esses interagem com os utilizadores e como esses se comportam, de acordo com suas necessidades.

O usuário passa, também, a definir suas próprias estratégias de busca e a conduzir suas necessidades informacionais. Nessa perspectiva, o arquivista precisa instruir e orientar o usuário no aperfeiçoamento de suas competências. Defende-se aqui a mediação da informação voltada para o usuário, não só para as suas necessidades informacionais, mas também, principalmente, para as competências que possuem e que podem empregar para tornarem-se independentes no processo de busca e uso da informação, o que influi diretamente na formação de usuários e extrapola a disponibilização e facilitação do acesso às informações. A partir dessa perspectiva, foram definidos os indicadores analisados (destacados em negrito).

Nesse sentido, ao procurar entender a necessidade informacional do usuário, os resultados indicam que a maior parte dos participantes declara que sua prioridade é saber do usuário de que informação ele necessita (45\%), seguido por ajudá-lo a definir e articular a sua própria necessidade (40\%). Aqui, é possível traçar um paralelo entre a mediação da informação e as competências em comunicação, visto a necessidade evidente do diálogo e da negociação entre o arquivista e o usuário para que seja compreendida ou mesmo definida a necessidade informacional em questão.

Um aspecto relevante a ser considerado é que apenas $2 \%$ consideram prioritário saber qual o uso será feito da informação que será disponibilizada ou mesmo entender as razões que motivaram a solicitação (4\%). Nesse sentido, observa-se que os arquivistas estão mais focados em possibilitar o acesso à informação do que necessariamente com o uso e a apropriação dessa informação. De acordo com Ribeiro (2010), o uso da informação também 
precisa ser considerado no contexto da mediação da informação pós-custodial e não só o acesso. Acredita-se que se preocupar com o uso da informação favorece o processo de mediação, uma vez que fornece meios para saber se tal processo é efetivo, avançando de uma mediação (fraca) que disponibiliza conteúdos para uma mediação (forte) que se afiança da apropriação da informação.

Desse modo, considerando que a atuação do arquivista vai além da simples disponibilização de informações, é preciso compreender quais ações são desenvolvidas para orientar a busca e o acesso às informações. Nessa perspectiva, os arquivistas foram questionados sobre quais ações relacionadas a esse indicador não são consideradas por eles como parte de sua responsabilidade enquanto mediador da informação.

Aproximadamente 39,6\% dos arquivistas não consideram incentivar os usuários a aplicar e/ou desenvolver suas habilidades operacionais para lidar com a tecnologia como parte de sua responsabilidade. Segue-se ensinar sobre as fontes e os formatos de informação (18,9\%). Entende-se que essas ações, assim como apresentar e explicar sobre os sistemas de busca (13,2\%) estão diretamente relacionadas a orientar os usuários quanto à busca e uso das informações. Sendo assim, não considerar tais ações implica em limitar o papel do arquivista enquanto mediador da informação na formação de usuários mais independentes no processo de busca e uso das informações.

Vê-se que orientar o processo de busca da informação foi a ação menos escolhida $(5,7 \%)$ pelos respondentes dentre as que não são de sua responsabilidade. Esta função mediadora está estabelecida, mas é importante avançar da disponibilização de conteúdos para a promoção do salto qualitativo nos usuários defendido por Neves (2011). Em outras palavras, é necessário criar condições favoráveis para que o usuário possa acessar e usar as informações pertinentes à sua necessidade. Isso envolve incentivar o usuário a empregar suas competências, ajudando-o a aperfeiçoá-las ou mesmo desenvolvê-las para que possa atender às suas próprias necessidades de informação. 
Os arquivistas também foram questionados sobre de quem seria a responsabilidade de avaliar a informação entregue ao usuário. A maioria acredita que a informação deve ser avaliada por ambos (63,2\%). Assim, o arquivista enquanto mediador deve avaliar o conteúdo junto com o usuário, ajudando-o a perceber se a informação é ou não pertinente. Em contraposição, 24,5\% atribui a avaliação da informação somente ao usuário, isentando-se da responsabilidade de avaliar se o conteúdo entregue é de fato pertinente à necessidade informacional de quem o solicitou. É verdade que os usuários vêm assumindo uma posição mais ativa, deixando de serem receptores passivos, mas isso não exclui o papel da mediação como apoio à avaliação da idoneidade dos conteúdos.

Ademais, 11,3\% dos arquivistas consideram-se os únicos responsáveis pela avaliação da informação disponibilizada no momento do atendimento, o que de certa forma acaba atribuindo ao usuário uma condição passiva de utilizador ou mesmo de recebedor da informação. Sabe-se que essa caracterização já não cabe, em geral, aos usuários de arquivo que tiveram seu perfil influenciado pela cultura participativa (JENKINS, 2009), tornaram-se mais ativos e protagonistas no processo de busca e uso das informações.

Retoma-se aqui a questão de que o arquivista também é responsável por orientar o uso da informação. Os participantes da pesquisa foram questionados sobre o que eles costumavam fazer após entregar uma informação solicitada ao usuário, para averiguar se há a preocupação em saber como o usuário utilizou as informações, se houve ou não assimilação do conteúdo e satisfação da necessidade informacional (Gráfico 7). 
Gráfico 7 - Uso da informação disponibilizada ao usuário

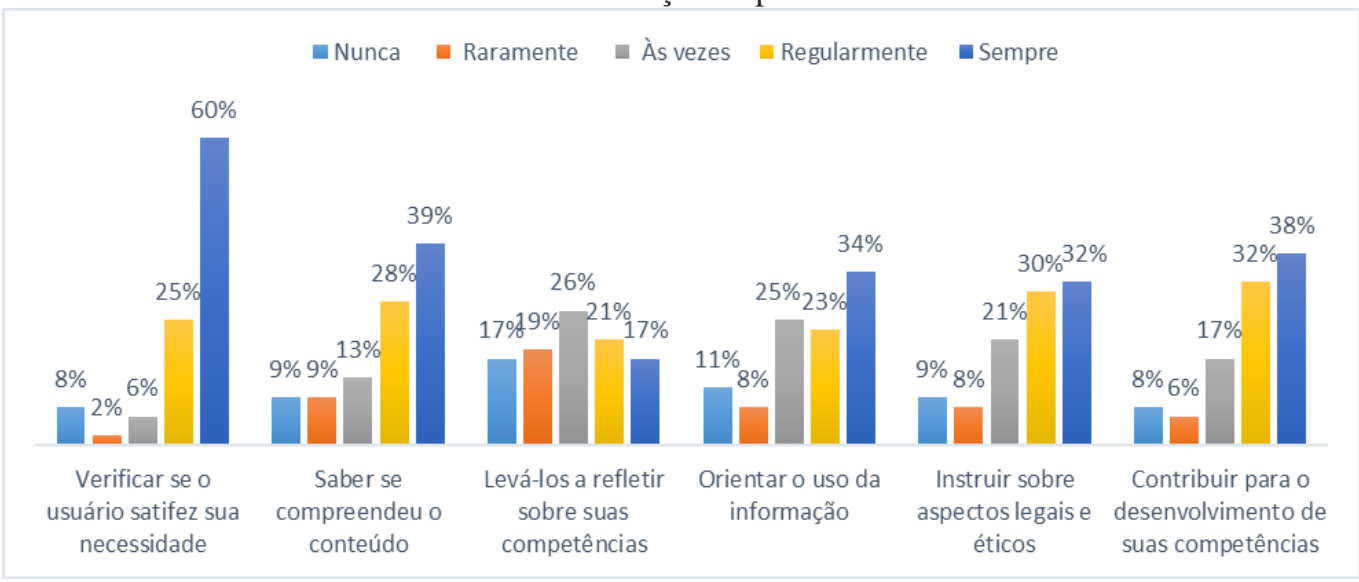

Fonte: Elaborado a partir dos dados da pesquisa.

Ao analisar os dados apresentados pelo Gráfico 7, observa-se que os arquivistas se mostram bastante preocupados em verificar se o usuário satisfez sua necessidade (60\%). No entanto, apenas $40 \%$ verificam se o conteúdo foi compreendido ou assimilado pelo usuário.

Aqui mais uma vez percebe-se que não é frequente entre os arquivistas a prática de ações ligadas à formação de usuários como, por exemplo, levar os usuários a refletir sobre suas competências no trato com a informação, orientar quanto ao uso da informação disponibilizada e instruir sobre aspectos legais e éticos envolvendo a informação. O que indica que, talvez, essas ações não sejam tidas como prioridade no atendimento ao usuário. Embora boa parte afirme que costuma, frequentemente, contribuir para tornar os usuários independentes no processo de busca e uso da informação, 38\% disseram o fazer sempre e 32\%, regularmente.

Dessa forma, observa-se que satisfazer a necessidade informacional dos usuários é uma das maiores preocupações dos arquivistas ao mediar a informação, e junto a isso está a preocupação de avaliar a informação disponibilizada ao usuário como uma forma de avaliar, também, a sua atuação e se o atendimento foi efetivo. Assim, também é consensual entre os arquivistas que orientar a busca e o acesso às informações é uma prática inerente às suas atribuições. 
No entanto, quando se fala no uso da informação feita pelo usuário não há essa mesma aceitação. A questão do uso da informação vai interferir diretamente na formação de usuários, uma vez que não se constatou um comportamento voltado que contribua para tornar os usuários independentes no processo de busca e uso da informação. As ações de mediação da informação empregadas pelos arquivistas ainda se mostram mais direcionadas à disponibilização de conteúdos, em vez da formação de usuários.

\section{Conclusão}

De uma forma geral, as competências infocomunicacionais dos arquivistas estão mais desenvolvidas no que diz respeito a identificar a necessidade de informação, buscar e avaliar a informação (competências em informação) estabelecer e avaliar a comunicação (competências em comunicação). Contudo, os resultados dessa pesquisa apontam que alguns aspectos precisam ser melhorados, dentre eles estão: enfrentar obstáculos para se apropriar das informações que acessa e apreender sentido, produzir novas informações (competências em informação); criar uma postura mais participativa e colaborativa e, então, desenvolver laços sociais e construir conhecimento em colaboração (competências em comunicação).

Observa-se que o emprego das competências infocomunicacionais pelos arquivistas, bem como suas deficiências e dificuldades refletem-se no modo como eles medeiam a informação e orientam o usuário na satisfação de suas necessidades informacionais. Quanto mais desenvolvidas estiverem tais competências, maior o nível de consciência participativa e colaborativa e, portanto, mais efetiva torna-se a sua atuação no processo de formação de usuários.

As competências infocomunicacionais estão intimamente ligadas ao fator metacognitivo que envolve a avaliação que o arquivista faz de suas próprias competências, e o possibilita a ampliar sua autopercepção enquanto mediador e a estar mais propício a construir uma conexão entre o que sabe e o que pode transmitir ou aprender com o outro. $\mathrm{O}$ arquivista que procura empregar suas 
competências no fazer profissional reconhece que, para além de desenvolver suas próprias competências, o seu papel envolve incentivar e propiciar maneiras de promover o desenvolvimento de tais competências também entre os usuários.

Dessa forma, alguns aspectos em relação à atuação do arquivista no processo de mediação da informação precisam ser melhorados. Este tem que desenvolver mais o seu perfil de mediador. Trata-se de uma mudança de papel: o arquivista precisa ter um perfil mais colaborativo e reconhecer que o seu papel não é somente atender às necessidade de informação de determinado usuário, mas também sim contribuir com a formação de usuários competentes para lidar com o ambiente informacional hodierno. Assim, terá sua função de mediação potencializada e muito mais valorizada, considerando a rápida transformação e inovação desses ambientes.

\section{Referências}

ALMEIDA JÚNIOR, O. Mediação da informação e múltiplas linguagens. Pesquisa em Ciência da Informação, João Pessoa, v. 2, n. 1, p. 89-103, 2009.

BORGES, J. Participação política, internet e competências

infocomunicacionais: estudo com organizações da sociedade civil de Salvador. 2011. Tese (Doutorado em Comunicação) - Universidade Federal da Bahia, Salvador, 2011.

BORGES, J; BRANDÃO, G. Competências em comunicação no ciberespaço: um novo desafio às organizações da sociedade civil. In: OLIVEIRA, L; BALDI, V. A insuportável leveza da web: retóricas, dissonâncias e práticas na sociedade em rede. Salvador: EDUFBA, 2014.

COMITÊ GESTOR DA INTERNET NO BRASIL. Pesquisa sobre o uso das tecnologias de informação e comunicação no Brasil: TIC Centros públicos de acesso 2013. São Paulo, 2014.

DUDZIAK, E. Competência Informacional e midiática no ensino superior: desafios e propostas para o Brasil. Prisma.Com, Porto, n. 13, p. 1-19, 2010.

GONZÁLEZ FERNÁNDEZ-VILLAVICENCIO, N. Alfabetización para una cultura social, digital, mediática y en red. Revista Española de Documentación Científica, Madrid, n. especial, p. 17-45, 2012. 
GUERRA, I. C. Pesquisa qualitativa e análise de conteúdo: sentidos e formas de uso. Cascais: Principia, 2010.

JACOBSON, T. E.; MACKEY, T. P. Proposing a metaliteracy model to redefine information literacy. Communications in Information Literacy, Tulsa, v. 7, n. 2, p. 84-91, 2013.

JENKINS, H. Confronting the challenges of participatory culture: media education for the 21st century. Cambridge: MIT Press, 2009.

MACKEY, T.P.; JACOBSON, T. E. Metaliteracy: reinventing information literacy to empower learners. London: Facet, 2014.

MIRANDA, S. Como as necessidades de informação podemse relacionarcom as competências informacionais. Ciência da Informação, Brasília, v. 35, n. 3, p. 99-114, 2006.

NEVES, B. C. Mediação da informação para agentes sociodigitais: o salto.

Ciência da Informação, Brasília, v. 40, n. 3, p. 413-424, 2011.

RIBEIRO, F. Da mediação passiva à mediação pós-custodial: o papel da Ciência da Informação na sociedade em rede. Informação \& Sociedade: Estudos, João Pessoa, v. 20, n. 1, p. 63-70, 2010

SIEMENS, G. Conociendo el conocimiento. [S.1.]: Nodos Ele, 2010.

SILVA, A. M. Mediações e mediadores em Ciência da Informação.

Prisma.Com, Porto, n. 9, p. 1-36, 2010.

WOLTON, D. É preciso salvar a comunicação. São Paulo: Paulus, 2006.

\title{
The contribution of infocommunication competences in the work of the archivist as a mediator
}

\begin{abstract}
The objective of this article is to analyze the infocommunication competences developed by archivists and their contribution in the mediation process and in the training of information users. The research has a qualitativequantitative approach. Regarding the methodological procedures, a bibliographical and field research was adopted, with the online questionnaire used as data collection technique; the sample is composed of 53 archivists who work in the Brazilian archives (public and private). The data analysis is based primarily on the categories of analysis and in indicators developed to assess the infocommunication competences of archivists. The results showed that, in general, the infocommunication competences are more developed to identify the
\end{abstract}


need for information, search and evaluate information, establishing and evaluating communication. However, we identified that archivists have difficulties both to appropriate the information they have access to and to act in a participatory and collaborative way. In this way, we concluded that the development of these competences directly influences the perception of their role as mediator of information and also in their performance.

Keywords: Infocommunication skills. Archivist. Mediation of information.

Recebido: 27/09/2017

Aceito: $27 / 10 / 2017$

${ }^{1}$ Tradução livre de "[...] model for information literacy to advance critical thinking and reflection in social media, open learning settings, and online communities".

${ }^{2}$ Central to the metaliteracy model is a metacognitive component that encourages learners to continuously reflect on their own thinking and literacy development in these fluid and networked spaces. This approach leads to expanded competencies for adapting to the ongoing changes in emerging technologies and for advancing critical thinking and empowerment for producing, connecting, and distributing information as independent and collaborative learners.

${ }^{3}$ En lugar de ver el conocimiento desde una única perspectiva (el filtro), nosotros como individuos podemos contribuir con nuestras opiniones y puntos de vista a extender la profundidad (diversidad) de nuestro entendimiento. El conocimiento puede expresarse ahora a través del conjunto de los individuos, un crescendo ensordecedor de opiniones y puntos de vista opuestos y complementarios.

${ }^{4}$ Tradução livre de "[...] la capacidad de colaboración, socialización y de 'hacer cosas juntos'. Esperamos co-crear y experimentar los modelos de flujo bidireccionales de uso compartido del conocimiento y su difusión. Nuestras identidades están expuestas, a disposición de quien quiera explorarlas". 